\title{
Slug tests in partially penetrating wells
}

\author{
Zafar Hyder, James J. Butler, Jr., Carl D. McElwee, and Wenzhi Liu \\ Kansas Geological Survey, University of Kansas, Lawrence
}

\begin{abstract}
A semianalytical solution is presented to a mathematical model describing the flow of groundwater in response to a slug test in a confined or unconfined porous formation. The model incorporates the effects of partial penetration, anisotropy, finiteradius well skins, and upper and lower boundaries of either a constant-head or an impermeable form. This model is employed to investigate the error that is introduced into hydraulic conductivity estimates through use of currently accepted practices (i.e., Hvorslev, 1951; Cooper et al., 1967) for the analysis of slug-test response data. The magnitude of the error arising in a variety of commonly faced field configurations is the basis for practical guidelines for the analysis of slug-test data that can be utilized by field practitioners.
\end{abstract}

\section{Introduction}

The slug test is one of the most commonly used techniques by hydrogeologists for estimating hydraulic conductivity in the field [Kruseman and de Ridder, 1989]. This technique, which is quite simple in practice, consists of measuring the recovery of head in a well after a near instantaneous change in water level at that well. Approaches for the analysis of the recovery data collected during a slug test are based on analytical solutions to mathematical models describing the flow of groundwater to/from the test well. Over the last 30 years, solutions have been developed for a number of test configurations commonly found in the field. Chirlin [1990] summarizes much of this past work.

In terms of slug tests in confined aquifers, one of the earliest proposed solutions was that of Hvorslev [1951], which is based on a series of simplifying assumptions concerning the slug-induced flow system (e.g., negligible specific storage, finite effective radius). Much of the work following Hvorslev has been directed at removing one or more of these simplifying assumptions. Cooper et al. [1967] developed a fully transient solution for the case of a slug test in a well fully screened across a confined aquifer. Moench and Hsieh [1985] extended the solution of Cooper et al. to the case of a fully penetrating well with a finite radius well skin. A number of workers [e.g., Dougherty and Babu, 1984; Hayashi et al., 1987] have developed solutions for slug tests in wells partially penetrating isotropic, confined aquifers. Butler and $M c E l$ wee [1990] presented a solution for slug tests in wells partially penetrating confined aquifers that incorporates the effects of anisotropy and a finite-radius skin at the test well. In most field applications, the methods of $H$ vorslev [1951] or Cooper et al. [1967] are used. The error that is introduced into hydraulic conductivity estimates by employing these models in conditions where their assumptions are inappropriate has not yet been fully evaluated. Note that Nguyen and Pinder [1984] proposed a method for the analysis of data from slug tests in wells partially penetrating confined aquifers that has received a fair amount of use. Recently, however, Butler and Hyder [1993] have shown

Copyright 1994 by the American Geophysical Union.

Paper number 94WR01670.

0043-1397/94/94WR-01670\$05.00 that the parameter estimates obtained using this approach must be viewed with considerable skepticism owing to an error in the analytical solution upon which the model is based.

In terms of slug tests in unconfined aquifers, solutions to the mathematical model describing flow in response to the induced disturbance are difficult to obtain because of the nonlinear nature of the model in its most general form. Currently, most field practitioners use the technique of Bouwer and Rice [1976; Bouwer, 1989], which employs empirical relationships developed from steady state simulations using an electrical analog model, for the analysis of slug tests in unconfined flow systems. Dagan [1978] presents an analytical solution based on assumptions similar to those of Bouwer and Rice [1976]. Amoozegar and Warrick [1986] summarize related methods employed by agricultural engineers. All of these techniques result from the application of several simplifying assumptions to the mathematical description of flow to a well in an unconfined aquifer (e.g., negligible specific storage, finite effective radius, representation of the water table as a constant-head boundary). As with the confined case, the ramifications of these assumptions have not yet been fully evaluated.

In this paper a semianalytical solution is presented to a mathematical model describing the flow of groundwater in response to an instantaneous change in water level at a well screened in a porous formation. The model incorporates the effects of partial penetration, anisotropy, finite-radius well skins of either higher or lower permeability than the formation as a whole, and upper and lower boundaries of either a constant-head or an impermeable form. This model can be employed for the analysis of data from slug tests in a wide variety of commonly met field configurations in both confined and unconfined formations. Although packers are not explicitly included in the formulation, earlier numerical work has shown that such a model can also be used for the analysis of multilevel slug-test data when packers of moderate length (0.75 $\mathrm{m}$ or longer) are employed [e.g., Bliss and Rushton, 1984; Butler et al., 1994a].

The major purpose of this paper is to use this solution to quantify the error that is introduced into parameter estimates as a result of using currently accepted practices for the analysis of response data from slug tests. The magnitude of 


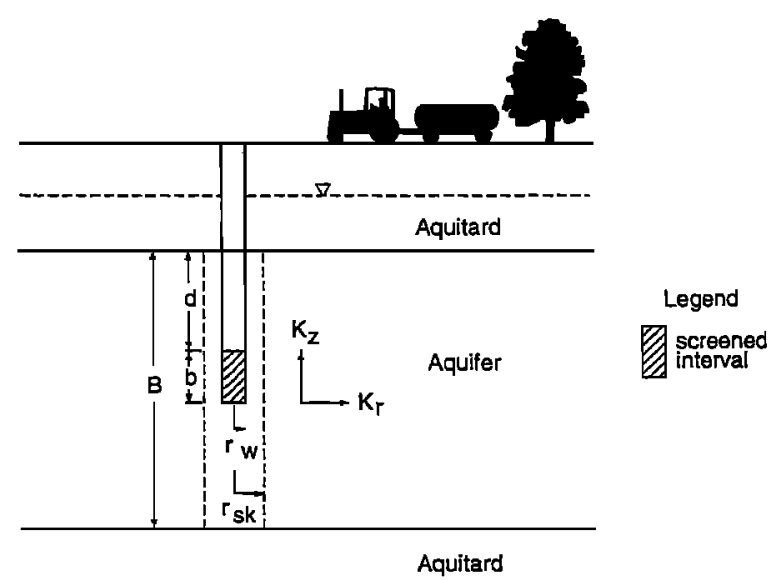

Figure 1. Cross-sectional view of a hypothetical confined aquifer (notation explained in text).

the error arising in a variety of commonly met field configurations serves as the basis for practical guidelines that can be utilized by field practitioners. Although such an investigation of parameter error could be carried out using either a numerical or analytical model, the analytical model described in the previous paragraph is employed here in order to provide a convenient alternative for data analysis when the error introduced by conventional approaches is deemed too large for a particular application.

\section{Statement of Problem}

The problem of interest here is that of the head response, as a function of $r, z$, and $t$, produced by the instantaneous introduction of a pressure disturbance into the screened or open section of a well. For the purposes of this initial development, the well will be assumed to be located in the confined aquifer shown in Figure 1. Note that, as shown on Figure 1, there is a well skin of radius $r_{\text {sk }}$ that extends through the full thickness of the aquifer. The skin has transmissive and storage properties that may differ from the formation as a whole. Flow properties are assumed uniform within both the skin and formation, although the vertical $\left(K_{z}\right)$ and radial $\left(K_{r}\right)$ components of hydraulic conductivity may differ.

The partial differential equation representing the flow of groundwater in response to an instantaneous change in water level at a central well screened in a porous formation is the same for both the skin and the aquifer and can be written as

$$
\frac{\partial^{2} h_{i}}{\partial r^{2}}+\frac{1}{r} \frac{\partial h_{i}}{\partial r}+\left(\frac{K_{z i}}{K_{r i}}\right) \frac{\partial^{2} h_{i}}{\partial z^{2}}=\left(\frac{S_{s i}}{K_{r i}}\right) \frac{\partial h_{i}}{\partial t}
$$

where $h_{i}$ is the head in zone $i[L] ; S_{s i}$ is the specific storage of zone $i[1 / L] ; K_{z i}, K_{r i}$ are the vertical and radial components, respectively, of the hydraulic conductivity of zone $i$ $[L / T] ; t$ is time $[T] ; r$ is radial direction $[L] ; z$ is vertical direction, $z=0$ at the top of the aquifer and increases downward $[L] ; i$ is the zone designator, for $r \leq r_{\mathrm{sk}}, i=1$, and for $r_{\mathrm{sk}} \leq r, i=2$; and $r_{\mathrm{sk}}$ is the outer radius of skin [ $\left.L\right]$.

The initial conditions can be written as

$$
h_{1}(r, z, 0)=h_{2}(r, z, 0)=0 \quad r_{w}<r<\infty \quad 0<z<B
$$

$$
H(0)=H_{0}
$$

where $r_{w}$ is the screen radius $[L], B$ is aquifer thickness $[L]$, $H$ is level of water in well [ $L]$, and $H_{0}$ is height of initial slug, equal to level of water in well at $t=0(H(0)),[L]$.

The boundary conditions are the following:

$$
\begin{gathered}
h_{2}(\infty, z, t)=0 \quad t>0 \quad 0 \leq z \leq B \\
\frac{\partial h_{i}(r, 0, t)}{\partial z}=\frac{\partial h_{i}(r, B, t)}{\partial z}=0 \quad r_{w}<r<\infty \quad t>0 \\
\frac{1}{b} \int_{d}^{d+b} h_{1}\left(r_{w}, z, t\right) d z=H(t) \quad t>0
\end{gathered}
$$

$2 \pi r_{w} K_{r 1} \frac{\partial h_{1}\left(r_{w}, z, t\right)}{\partial r}=\frac{\pi r_{c}^{2}}{b} \frac{d H(t)}{d t} \square(z) \quad t>0$

where $d$ is distance from the top of the aquifer to the top of the screen $[L] ; b$ is screen length $[L] ; r_{c}$ is radius of well casing (casing and screen do not have to be of equal radius) $[L]$; and $\square(z)$ is the boxcar function, equal to zero at $z<d$, $z>b+d$, and equal to 1 otherwise.

In order to ensure continuity of flow between the skin and the formation, auxiliary conditions at the skin-formation boundary $\left(r=r_{\text {sk }}\right)$ must also be met:

$$
\begin{array}{r}
h_{1}\left(r_{\text {sk }}, z, t\right)=h_{2}\left(r_{\text {sk }}, z, t\right) \quad 0 \leq z \leq B \quad t>0 \\
K_{r 1} \frac{\partial h_{1}\left(r_{\text {sk }}, z, t\right)}{\partial r}=K_{r 2} \frac{\partial h_{2}\left(r_{\text {sk }}, z, t\right)}{\partial r} \\
0 \leq z \leq B \quad t>0
\end{array}
$$

Equations (1)-(9) approximate the flow conditions of interest here. Appendix A provides the details of the solution derivation. In summary, the approach employs a series of integral transforms (a Laplace transform in time and a finite Fourier cosine transform in the $z$ direction) to obtain functions in transform space that satisfy the transform-space analogs of (1)-(9). The transform-space function that is obtained for the head in a partially penetrating well with a finite-radius well skin in an anisotropic confined aquifer can be written in a nondimensional form as

$$
\Phi(p)=\frac{(\gamma / 2) \Omega}{[1+(\gamma / 2) p \Omega]}
$$

where $\Phi(p)$ is the Laplace transform of $H(t) / H_{0}, p$ is the Laplace-transform variable, $\alpha=\left(2 r_{w}^{2} S_{s 2} b\right) / r_{c}^{2}, \gamma=K_{r 2}$ $K_{r 1}$, and

$$
\Omega=\int_{\zeta}^{\zeta+1}\left\{F_{c}^{-1}\left[F_{c}(\omega) f_{1}\right]\right\} d \eta
$$

where $\omega$ is the Fourier-transform variable, $F_{c}(\omega)$ is the finite Fourier cosine transform of $\square(z), F_{c}^{-1}$ is the inverse finite Fourier cosine transform,

$$
f_{1}=\frac{\left[\Delta_{2} K_{0}\left(\nu_{1}\right)-\Delta_{1} I_{0}\left(\nu_{1}\right)\right]}{\nu_{1}\left[\Delta_{2} K_{1}\left(\nu_{1}\right)+\Delta_{1} I_{1}\left(\nu_{1}\right)\right]},
$$


$\eta=z / b ; \zeta=d / b ; \nu_{i}=\left(\psi_{i}^{2} \omega^{2}+R_{i} p\right)^{0.5} ; \psi_{i}=\left(A_{i} / a^{2}\right)^{0.5}$ $A_{i}=K_{z i} / K_{r i} ; a=b / r_{w} ; R_{1}=\gamma \alpha / 2 \lambda ; R_{2}=\alpha / 2 ; \lambda=$ $S_{s 2} / S_{s 1}$

$$
\begin{gathered}
\Delta_{1}=K_{0}\left(\nu_{1} \xi_{\mathrm{sk}}\right) K_{1}\left(\nu_{2} \xi_{\mathrm{sk}}\right)-\left(\frac{N}{\gamma}\right) K_{0}\left(\nu_{2} \xi_{\mathrm{sk}}\right) K_{1}\left(\nu_{1} \xi_{\mathrm{sk}}\right) ; \\
\Delta_{2}=I_{0}\left(\nu_{1} \xi_{\mathrm{sk}}\right) K_{1}\left(\nu_{2} \xi_{\mathrm{sk}}\right)+\left(\frac{N}{\gamma}\right) K_{0}\left(\nu_{2} \xi_{\mathrm{sk}}\right) I_{1}\left(\nu_{1} \xi_{\mathrm{sk}}\right) \\
N=\nu_{1} / \nu_{2} \quad \xi_{\mathrm{sk}}=r_{\mathrm{sk}} / r_{w} .
\end{gathered}
$$

For the unconfined case the upper no-flow boundary condition in (5) is changed into a constant-head boundary condition, so the upper and lower boundary conditions are rewritten as

$$
\begin{array}{ccc}
h_{i}(r, 0, t)=0 & r_{w}<r<\infty & t>0 \\
\frac{\partial h_{i}(r, B, t)}{\partial z}=0 & r_{w}<r<\infty & t>0
\end{array}
$$

Appendix A also provides the details of the solution derivation for the unconfined case. The transform-space function that is obtained for the head in a partially penetrating well with a finite-radius well skin in an anisotropic unconfined aquifer can be written in a nondimensional form as

$$
\Phi_{\mathrm{uc}}(p)=\frac{(\gamma / 2) \Omega^{*}}{\left[1+(\gamma / 2) p \Omega^{*}\right]}
$$

where $\Phi_{\mathrm{uc}}(p)$ is the Laplace transform of $H(t) / H_{0}$ for the unconfined case;

$$
\Omega^{*}=\int_{\zeta}^{\zeta+1}\left\{F_{s}^{-1}\left[F_{s}\left(\omega^{*}\right) f_{1}\right]\right\} d \eta
$$

$F_{s}\left(\omega^{*}\right)$ is the modified finite Fourier sine transform of $\square(z)$; and $\omega^{*}$ is the Fourier transform variable for the modified sine transform.

For expressions of the complexity of (10) and (13), the analytical back transformation from transform space to real space is only readily performed under quite limited conditions. In the general case the transformation is best performed numerically. Numerical evaluation of the Fourier transforms and their inversions was done here using discrete Fourier transforms [Brigham, 1974], thereby allowing computationally efficient fast Fourier transform techniques [Cooley and Tukey, 1965] to be utilized. This approach, which is briefly outlined in Appendix B, did not introduce significant error into the inversion procedure. An algorithm developed by Stehfest [1970], which has been found to be of great use in hydrologic applications [Moench and Ogata, 1984], was employed to perform the numerical Laplace inversion.

Several checks were performed in order to verify that (10) and (13) are solutions to the mathematical model outlined here. Substitution of (10) and (13) into the respective transform-space analogs of (1)-(9) and (11)-(12) demonstrated that the proposed solutions honor the governing equation and auxiliary conditions in all cases. In addition, if the test well is assumed to be fully screened across an isotropic, confined aquifer, (10) reduces to the Laplace-space form of the solutions of Moench and Hsieh [1985] and Cooper et al.

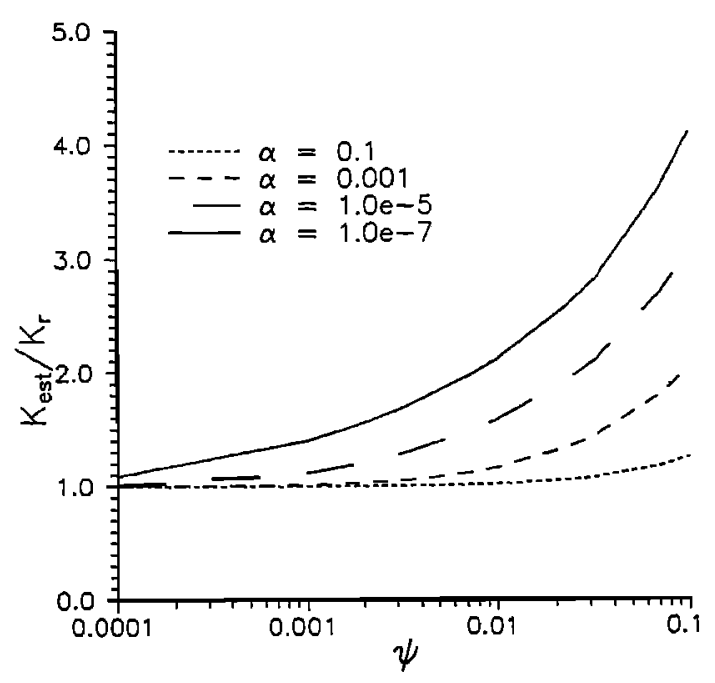

Figure 2. Plot of conductivity ratio (Cooper et al. estimate $\left(K_{\text {est }}\right)$ over actual conductivity $\left.\left(K_{r}\right)\right)$ versus $\psi\left(\left(K_{z} / K_{r}\right)^{1 / 2} /\right.$ $\left.\left(b / r_{w}\right)\right)$ as a function of $\alpha\left(\left(2 r_{w}^{2} S_{s} b\right) / r_{c}^{2}\right)$ for the case of a well screened near the center of a very thick aquifer $(\beta \approx 64, \zeta \approx$ 32).

[1967] for the skin and no-skin cases, respectively. Similarly, if the test well is assumed to be partially screened across an isotropic, confined aquifer, (10) reduces to the Laplacespace form of the solution of Dougherty and Babu [1984, equation (62)]. Butler et al. [1993b] describe additional checks performed with a numerical model to verify the solutions proposed here.

\section{Ramifications for Data Analysis}

As discussed in the introduction, the primary purpose of this paper is to evaluate the error that is introduced into parameter estimates through use of currently accepted practices to analyze response data from slug tests performed in conditions commonly faced in the field. This evaluation is carried out by using (10) and (13) to simulate a series of slug tests. The simulated response data are analyzed using conventional approaches. The parameter estimates are then compared with the parameters employed in the original simulations to assess the magnitude of the error introduced into the estimates through use of a particular approach for the data analysis. The simulation and analysis of slug tests were performed in this work using SUPRPUMP, an automated well-test analysis package developed at the Kansas Geological Survey [Bohling and McElwee, 1992].

\section{Partial Penetration Effects}

The first factor examined here was the effect of partial penetration on parameter estimates in a homogeneous aquifer (no-skin case). Figure 2 displays a plot of the hydraulic conductivity ratio $\left(K_{\text {est }} / K_{r}\right)$ versus $\psi$, where $\psi$ is the square root of the anisotropy ratio $\left(K_{z} / K_{r}\right)^{1 / 2}$ over the aspect ratio $\left(b / r_{w}\right)$, for a configuration in which the upper and lower boundaries are at such a large distance from the screened interval that they have no effect $(\beta=B / b \approx 64, \zeta=d / b \approx$ 32 ). In this case the hydraulic conductivity estimates are obtained using the solution of Cooper et al. [1967], which assumes that the well is fully screened across the aquifer (i.e., flow is purely radial). Figure 2 shows that the error 

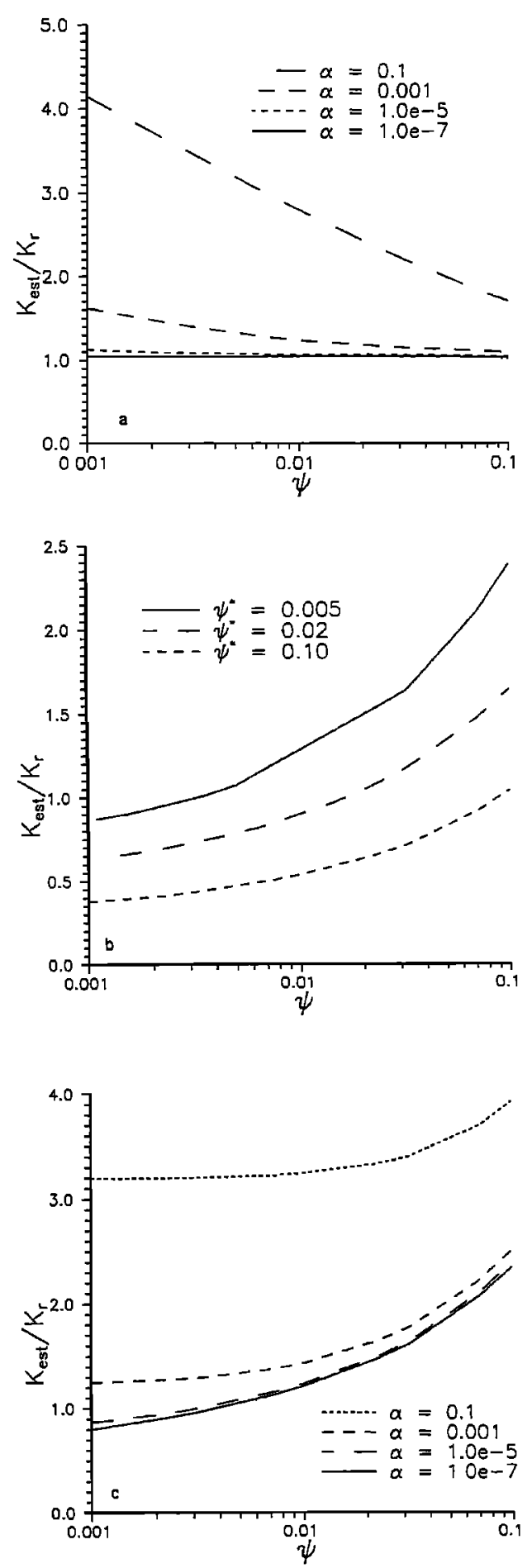

Figure 3. Plot of conductivity ratio (Hvorslev estimate $\left(K_{\text {est }}\right)$ over actual conductivity $\left.\left(K_{r}\right)\right)$ versus $\psi\left(\left(K_{z} / K_{r}\right)^{1 / 2} /\right.$ $\left.\left(b / r_{w}\right)\right)$ for the case of a well screened near the center of a very thick aquifer $(\beta \approx 64, \zeta \approx 32$ ). (a) Hvorslev estimates obtained with (14) (anisotropy ratio known) as a function of $\alpha\left(\left(2 r_{w}^{2} s_{s} b\right) / r_{c}^{2}\right)$. (b) Hvorslev estimates obtained with (14) (anisotropy ratio unknown) as a function of $\psi^{*}$ ( $\psi$ term with an assumed anisotropy ratio) for $\alpha=1.0 \times 10^{-5}$. (c) Hvorslev estimates obtained with the fully penetrating well variant of the Hvorslev model (assuming an effective radius of $\left.200 r_{w}\right)$ as a function of $\alpha\left(\left(2 r_{w}^{2} S_{s} b\right) / r_{c}^{2}\right)$. arising from the radial flow assumption diminishes with decreases in $\psi$. This is as expected, since $\psi$ reflects the proportion of vertical to radial flow in the slug-induced flow system. Decreases in $\psi$ correspond to decreases in the anisotropy ratio or increases in the aspect ratio, the effect of both of which is to constrain the slug-induced flow to the interval bounded by the top and bottom of the well screen (i.e., the proportion of radial flow increases). In addition, Figure 2 shows that the error in the conductivity estimates decreases greatly with increases in $\alpha$, the dimensionless storage parameter. This is in keeping with the results of Hayashi et al. [1987], who noted that, for a constant aspect ratio, vertical flow decreases with increases in the storage parameter. Based on Figure 2, it is evident that application of the Cooper et al. solution to data from slug tests performed in conditions where $\psi$ is less than about 0.003 should introduce little error into the conductivity estimates. For isotropic to slightly anisotropic systems, this $\psi$ range corresponds to aspect ratios greater than about 250 . Only in the case of a very low dimensionless storage parameter will significant error $(>25 \%$ ) be introduced into the estimates. Note that Figure 2 should be considered an extension of the findings of Hayashi et al. [1987] to the case of slug tests in open wells, a more common configuration for groundwater applications than the shut-in pressurized slug test configuration that they examined.

Currently, the most common method for analysis of slug tests in partially penetrating wells in confined aquifers is that proposed by Hvorslev [1951]. Hvorslev developed a model that can be used for the analysis of slug tests performed in a screened interval of finite length in a uniform, anisotropic, vertically unbounded medium. Figure $3 a$ displays a plot analogous to Figure 2 for the case of the Hvorslev model being used to obtain the conductivity estimates. Note that the Hvorslev model requires the use of a "shape factor," which is related to the geometry of the well intake region. The shape factor used in Figure $3 a$ is that for case 8 described by Hvorslev [1951] and results in the following expression for the radial component of hydraulic conductivity:

$$
K_{\mathrm{HV}}=\frac{r_{c}^{2} \ln \left\{1 /(2 \psi)+\left[1+(1 /(2 \psi))^{2}\right]^{1 / 2}\right\}}{2 b T_{0}}
$$

where $K_{\mathrm{HV}}$ is the estimate for the radial component of hydraulic conductivity obtained using the Hvorslev model and $T_{0}$ is the basic time lag, the time at which a normalized head of 0.37 is reached. As the aspect ratio gets large $(1 / 2 \psi$ gets large), (14) will reduce to Hvorslev's expression for a fully penetrating well (case 9) if the effective radius (distance beyond which the slug-induced disturbance has no effect on heads) is set equal to the screen length in case 9. Note that the anisotropy ratio, which appears in the $\psi$ term, and $K_{\mathrm{HV}}$ are perfectly correlated in (14), so these parameters cannot be estimated independently.

In Figure 3a, all analyses were performed using (14) while assuming that the anisotropy ratio was known. Given the difficulty of reliably estimating the degree of anisotropy in natural systems, this assumption must be considered rather unrealistic. Therefore, the analyses were repeated assuming that the degree of anisotropy was not known. However, since the anisotropy ratio and $K_{\mathrm{HV}}$ cannot be estimated independently, some value for the anisotropy ratio must be 
assumed for the analysis. This assumption of an arbitrary anisotropy ratio will give rise to an apparent $\psi\left(\psi^{*}\right)$ value, which is the square root of the assumed anisotropy ratio over the aspect ratio. Figure $3 \mathrm{~b}$ displays results obtained for slug tests analyzed using different $\psi^{*}$ values. When considered in order of decreasing magnitude, the $\psi^{*}$ curves correspond to aspect ratios of 10,50 , and 200 , respectively, for the case of an assumed anisotropy ratio of 1 (a common assumption in field applications). These curves will apply to different aspect ratios when an anisotropy ratio other than 1 is assumed.

Often, field analyses are performed using the fully penetrating well model of Hvorslev (case 9). For this approach, some assumption must be made concerning the effective radius of the slug test. In a frequently cited publication, the U.S. Department of the Navy [1961] recommends that an effective radius of 200 times the well radius be employed. Figure $3 c$ displays the error that is introduced into conductivity estimates when that recommendation is adopted.

Figure 3a indicates that the estimates provided by (14) will be reasonable for moderate to small values of dimensionless storage if the anisotropy ratio is known. At larger $\alpha$, however, the error introduced into the parameter estimates increases beyond the limit of what is considered reasonable for this investigation $( \pm 25 \%)$. Note that in Figure $3 a$, as in the remaining figures of this paper, the smallest $\psi$ value plotted is 0.001 . This is a result of the relationships shown in Figure 2, which indicate that, except in the case of very small values of dimensionless storage, the Cooper et al. model is the appropriate tool for analysis for $\psi$ values less than 0.001 .

Figure $3 b$ indicates that the quality of the estimates provided by (14) will be dependent on the assumed apparent $\psi\left(\psi^{*}\right)$ value for the case of an unknown anisotropy ratio. This figure demonstrates that for each $\psi^{*}$ value there is a range of actual $\psi$ for which the Hvorslev method will provide reasonable estimates. Although it is difficult to summarize the results of Figure $3 \mathrm{~b}$ succinctly, it is clear that, if the assumed anisotropy is moderately close to the actual anisotropy (within a factor of 2-3), the Hvorslev estimate will meet the criterion of reasonability employed here $( \pm 25 \%)$. It can be readily shown that the $\psi^{*}$ curves of Figure $3 \mathrm{~b}$ are related to one another by a simple multiplicative factor. This relationship enables curves for $\psi^{*}$ values other than those considered here to be generated by multiplying the $K_{\text {est }} / K_{r}$ ratio for one of the curves given in Figure $3 b$ by a factor consisting of the ratio of the natural logarithm term from (14) for the curve to be generated over the same term for the curve in Figure 3b. Although several standard references

Table 1. Tabulated Values of the Conductivity Ratio for the Plots of Figure 3c

\begin{tabular}{ccccc}
\hline$\psi$ & $\alpha=0.1$ & $\alpha=0.001$ & $\alpha=1.0 \times 10^{-5}$ & $\alpha=1.0 \times 10^{-7}$ \\
\hline $1.00 \times 10^{-3}$ & 3.196 & 1.249 & 0.867 & 0.803 \\
$2.23 \times 10^{-3}$ & 3.198 & 1.275 & 0.950 & 0.909 \\
$3.16 \times 10^{-3}$ & 3.203 & 1.293 & 1.001 & 0.964 \\
$7.07 \times 10^{-3}$ & 3.221 & 1.374 & 1.150 & 1.125 \\
$1.00 \times 10^{-2}$ & 3.244 & 1.429 & 1.233 & 1.210 \\
$2.22 \times 10^{-2}$ & 3.330 & 1.641 & 1.491 & 1.470 \\
$3.20 \times 10^{-2}$ & 3.399 & 1.774 & 1.638 & 1.615 \\
$7.10 \times 10^{-2}$ & 3.693 & 2.225 & 2.108 & 2.076 \\
$1.00 \times 10^{-1}$ & 3.920 & 2.508 & 2.388 & 2.347 \\
\hline
\end{tabular}

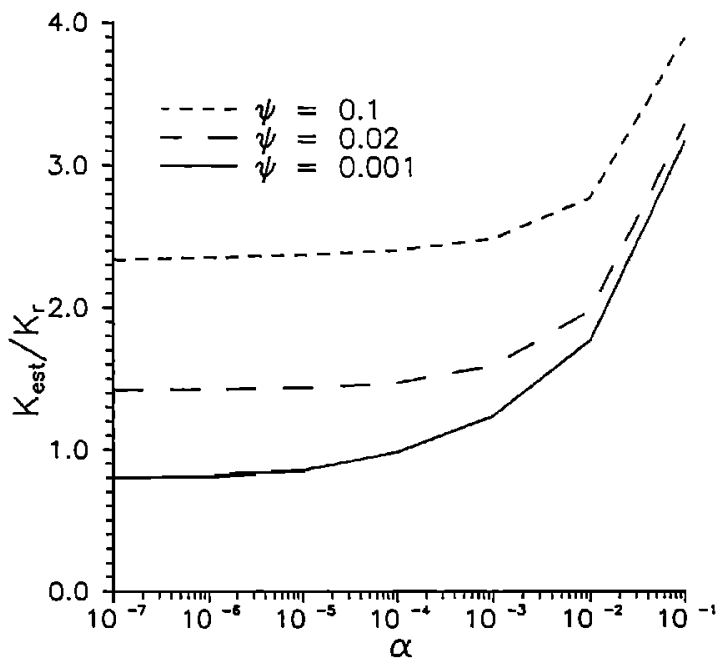

Figure 4. Plot of conductivity ratio (Hvorslev estimate ( $\left.K_{\text {est }}\right)$ over actual conductivity $\left.\left(K_{r}\right)\right)$ versus $\alpha\left(\left(2 r_{w}^{2} S_{s} b\right) / r_{c}^{2}\right)$ as a function of $\psi\left(\left(K_{z} / K_{r}\right)^{1 / 2} /\left(b / r_{w}\right)\right)$ for the case of a well screened near the center of a very thick aquifer $(\beta \approx 64 ; \zeta \approx$ $32 ; \psi^{*}=0.005$ )

[e.g., Freeze and Cherry, 1979] recommend use of the isotropic form of (14), these results indicate that such an approach is only appropriate in isotropic to slightly anisotropic systems. This recommendation will result in a consistent underprediction of hydraulic conductivity in moderately to strongly anisotropic systems.

Figure $3 \mathrm{c}$ indicates that the fully penetrating well model of Hvorslev (using an effective radius of 200 times the well radius) is appropriate in conditions where $\psi$ is less than about $\mathbf{0 . 0 1}$ for moderate to small values of dimensionless storage. This $\psi$ range corresponds to an aspect ratio greater than 100 for isotropic systems. For strongly anisotropic systems $\left(K_{z} / K_{r}\right.$ considerably less than 1$)$, the aspect ratios at which the fully penetrating well model becomes appropriate are much smaller. Given the form of the fully penetrating well model of Hvorslev employed here and the earlier discussed relationship between the fully and partially penetrating variants of the Hvorslev model, it should be clear that the curves on Figure 3c correspond to a $\psi^{*}$ value of 0.005 . Using the relationships discussed in the previous paragraph, the curves plotted in Figure $3 \mathrm{c}$ can be employed to generate all needed $\psi^{*}$ curves for common values of the dimensionless storage parameter. Table 1 presents the results from Figure $3 \mathrm{c}$ in a tabular form, so that the reader can generate the curve needed for a particular application. Since the $\psi^{*}$ curves can be readily related to one another, the results presented in the remainder of this paper will be for one particular $\psi^{*}$ value $\left(\psi^{*}=0.005\right)$, which as stated above, also corresponds to the fully penetrating well model of Hvorslev. The tabulated values for all the curves presented here are given by Hyder [1994].

Figures $3 a-3 c$ show that the quality of the Hvorslev estimates deteriorates rapidly as dimensionless storage increases above 0.001 . Figure 4 graphically displays the large errors that are introduced into parameter estimates as $\alpha$ approaches 1 for the same conditions as shown in Figure 3c. Clearly, the Hvorslev model must be used with extreme caution at large values of the dimensionless sterage param- 


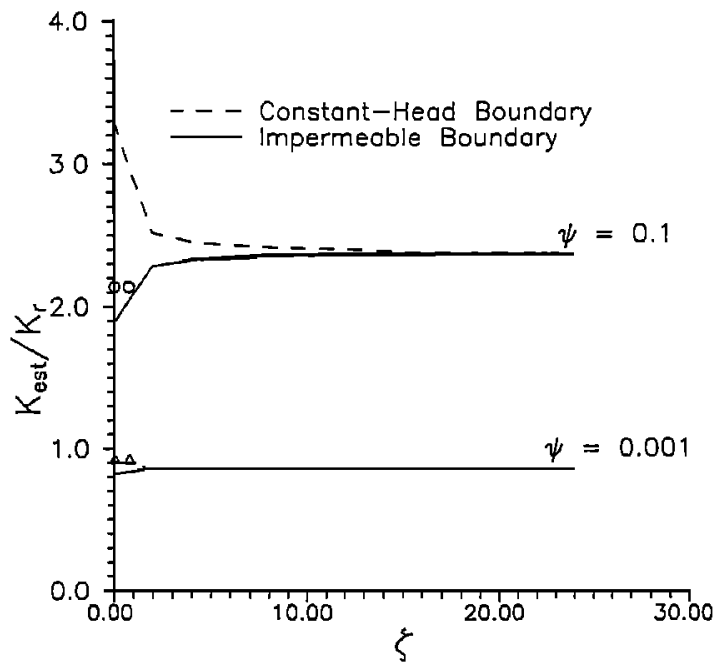

Figure 5. Plot of conductivity ratio (Hvorslev estimate $\left(K_{\text {est }}\right)$ over actual conductivity $\left(K_{r}\right)$ ) versus $\zeta(d / b)$ as a function of $\psi\left(\left(K_{z} / K_{r}\right)^{1 / 2} /\left(b / r_{w}\right)\right)$. Solid lines designate impermeable upper boundary; dashed lines designate constanthead upper boundary; circles and triangles designate estimates obtained using the semi-infinite variant of the Hvorslev model for $\psi$ values of 0.1 and 0.001 , respectively; $\beta \approx 64 ; \alpha=1.0 \times 10^{-5} ; \psi^{*}=0.005$.

eter. Since Figure 2 indicates that the Cooper et al. model provides excellent conductivity estimates at large values of dimensionless storage, the Cooper et al. model should always be employed when such dimensionless storage values are expected. As shown by Chirlin [1989], large values of dimensionless storage will often be reflected in a distinct concave upward curvature in a $\log$ head versus time plot. Note that the $\psi$ curves on Figure 4 become nearly horizontal as $\alpha$ decreases. Therefore the results that are discussed in this paper concerning the viability of the Hvorslev model at $\alpha$ values of $10^{-5}-10^{-7}$ should be very good approximations for conditions where $\alpha$ values are smaller than $10^{-7}$.

An important goal of this paper is to define guidelines for the field practitioner. Since in actual field applications the aspect ratio should be a known quantity, guidelines based on the magnitude of the aspect ratio would be preferred. Although the general lack of information concerning anisotropy and specific storage introduces uncertainty, the results of this section can be used to roughly define aspect ratio guidelines for the analysis of response data from slug tests in partially penetrating wells. Clearly, at large aspect ratios (greater than 250), the Cooper et al. [1967] model is the most appropriate tool for data analysis. In strongly anisotropic systems $\left(K_{z} / K_{r}\right.$ considerably less than 1$)$, the Cooper et al. model will be applicable at much smaller aspect ratios. Although it is difficult to accurately estimate the degree of anisotropy from slug-test response data, Butler et al. [1993a] present a simple approach that can be used to assess if significant anisotropy is present. In the general case, the fully penetrating well model of Hvorslev [1951] would be the best approach for analyzing response data from wells of aspect ratios between 100 and 250. At smaller aspect ratios the partially penetrating model of Hvorslev is best in the most general case. However, the most appropriate model for any particular application will depend on the anisotropy ratio and specific storage. If some reasonable estimates can be made about these parameters, Figures $2-4$ and Table 1 can be used to assess which method is most appropriate for that specific application. Note that the model of Cooper et al. should be employed at all aspect ratios when the dimensionless storage parameter is large.

\section{Boundary Effects}

The previous discussion has focused on the effects of partial penetration in a vertically infinite system. Although one might suspect that most natural systems can be considered as vertically infinite for the purposes of the analysis of response data from slug tests, there may be situations in which the upper and/or lower boundaries of the system influence the response data. Thus the next factor examined here was the effect of impermeable and constant-head boundaries in the vertical plane on parameter estimates. Figure 5 displays a plot of the hydraulic conductivity ratio versus the normalized distance to a boundary $(\zeta=d / b)$. Results are shown for both impermeable and constant-head boundaries. In all cases, an apparent $\psi\left(\psi^{*}\right)$ value of 0.005 is used to obtain the conductivity estimates. It is clear from Figure 5 that a boundary will only have a significant effect $(>25 \%)$ on parameter estimates when the screen is very close to the boundary (i.e., $\zeta<1-2$ ) and $\psi$ is relatively large. If there is any degree of anisotropy in hydraulic conductivity, the influence of the boundary will be considerably lessened. Note that Hvorslev [1951] also proposed a semiinfinite, partially penetrating well model (single impermeable boundary with screen extending to boundary) for slug tests. The equation for estimation of hydraulic conductivity in this case is the same as (14) except $\psi$ is used instead of $2 \psi$ in the logarithmic term. The circles and triangles in Figure 5 show the estimates that would be obtained using this model for the confined case. Clearly, the semi-infinite variant of the Hvorslev model is only necessary at large $\psi$ values (wells of small aspect ratios in isotropic aquifers). As the proportion of vertical flow decreases ( $\psi$ gets small), the semi-infinite model becomes slightly inferior to the vertically infinite form of the Hvorslev model. Although all of the parameter estimates in Figure 5 were obtained using the Hvorslev model, the method of Bouwer and Rice [1976] would normally be employed if an unconfined boundary is suspected. Hyder and Butler [1994] provide a detailed discussion of the error introduced into parameter estimates using the Bouwer and Rice model.

The above discussion focuses on results when only a single boundary is influencing the response data. In thin formations, one may face conditions when both the upper and lower boundaries are close enough to the screen to be affecting the slug-test responses. Figure 6 displays a plot of the hydraulic conductivity ratio versus normalized aquifer thickness $(\beta=B / b)$ for the case of a well screen located at the center of the unit. Clearly, in thin confined systems, the pair of impermeable boundaries will have a significant effect on Hvorslev estimates for relatively large values of $\psi$. In thin unconfined systems, the lower impermeable boundary acts in an opposite manner to the upper constant-head boundary, so that the estimates are more reasonable than in the single-boundary case.

The results of this section indicate that, except in cases of very thin formations $(\beta<10)$, screens located very close to a boundary $(\zeta<5)$, and large values of $\psi(>0.05)$, the 
assumption of a vertically infinite system introduces a very small amount of error into the parameter estimates obtained using the Hvorslev model. Thus the relationships presented in Figures 3 and 4 can be considered appropriate for the vast majority of field applications. Note that no analyses were performed in this section using the Cooper et al. [1967] model. In the previous section, a range of aspect ratios $(>250)$ was defined for which the Cooper et al. model would provide reasonable estimates. Since boundaries in the vertical plane will only introduce sizable errors into parameter estimates when there is a considerable component of vertical flow, the effects of boundaries will be very small if the Cooper et al. model is only applied over the previously defined range.

\section{Well-Skin Effects}

The results of the previous sections pertain to the case of slug tests performed in homogeneous formations. Often, however, as illustrated in Figure 1, well drilling and development create a disturbed, near-well zone (well skin) that may differ in hydraulic conductivity from the formation in which the well is screened. It is important to understand the effect of well skins on conductivity estimates in order to avoid using estimates representative of skin properties to characterize the formation as a whole.

Figure 7a illustrates the effect of a well skin on conductivity estimates obtained using the Hvorslev model $\left(\psi^{*}=\right.$ 0.005 ) for a broad range of contrasts between the conductivity of the skin and that of the formation. Clearly, the existence of a well skin can have a dramatic effect on the Hvorslev estimates. In the case of a skin less permeable than the formation, a conductivity estimate differing from the actual formation value by over an order of magnitude can easily be obtained. Figure 7a displays results for the case of a skin whose outer radius is twice that of the well screen $\left(\xi_{\text {sk }}=r_{\text {sk }} / r_{w}=2\right)$. Figure $7 \mathrm{~b}$ shows how the results depend on the thickness of the skin for the case of a skin 1 order of magnitude less conductive than the formation $(\gamma=10.0)$.

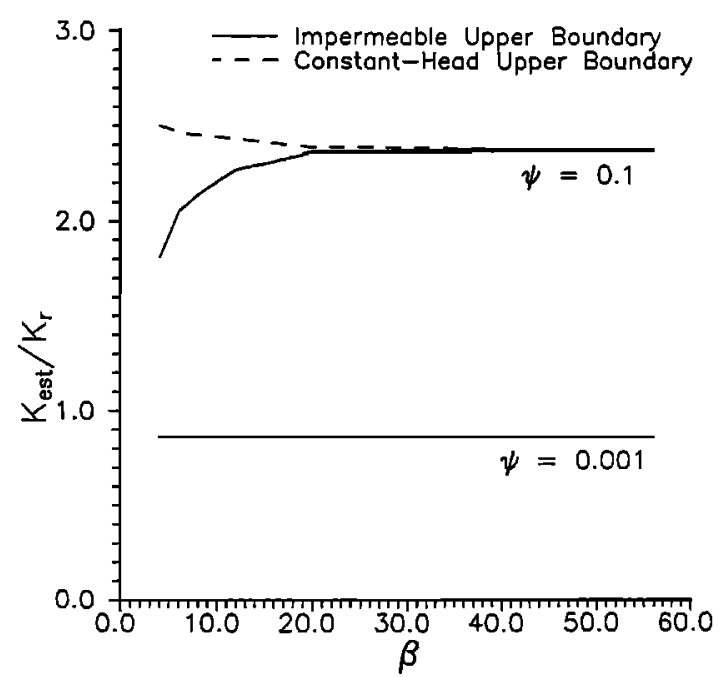

Figure 6. Plot of conductivity ratio (Hvorslev estimate $\left(K_{\text {est }}\right)$ over actual conductivity $\left(K_{r}\right)$ ) versus $\beta(B / b)$ as a function of $\psi\left(\left(K_{z} / K_{r}\right)^{1 / 2} /\left(b / r_{w}\right)\right)$. Solid lines designate impermeable upper boundary; dashed lines designate constanthead upper boundary; $\alpha=1.0 \times 10^{-5} ; \psi^{*}=0.005$.
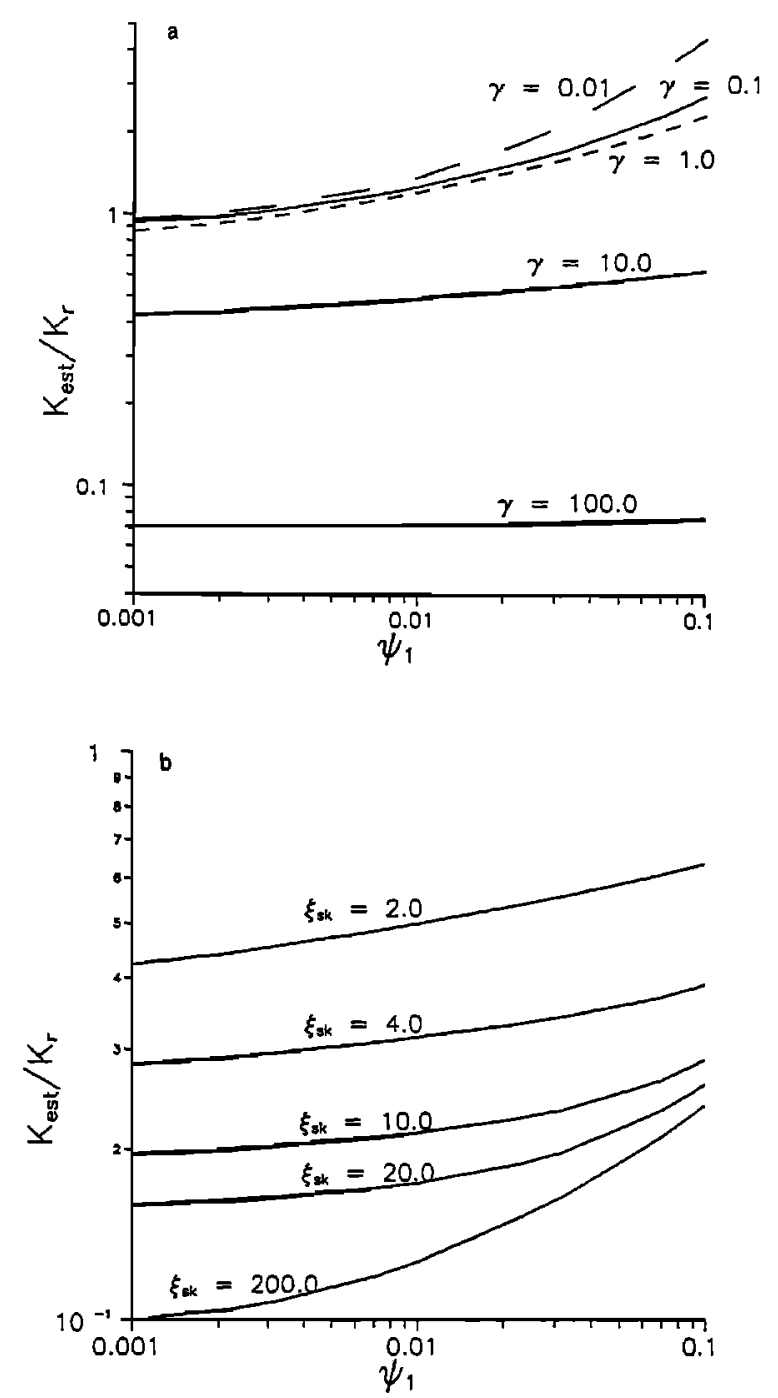

Figure 7. Plot of conductivity ratio (Hvorslev estimate $\left(K_{\text {est }}\right)$ over actual formation conductivity $\left(K_{r}\right)$ ) versus $\psi_{1}\left(\left(K_{z 1} / K_{r 1}\right)^{1 / 2} /\left(b / r_{w}\right)\right)$ for the case of high and low conductivity well skins $\left(\beta \approx 64, \zeta \approx 32, \alpha=1.0 \times 10^{-5}, \psi^{*}=\right.$ $0.005, \psi_{1}=\psi_{2}, \lambda=1$ ). (a) Hvorslev estimates as a function of $\gamma\left(K_{r 2} / K_{r 1}\right)$ for $\xi_{\text {sk }}=2$. (b) Hvorslev estimates as a function of $\xi_{\text {sk }}\left(r_{\text {sk }} / r_{w}\right)$ for $\gamma=10.0$.

Note that when the skin radius equals the effective radius assumed in the Hvorslev fully penetrating well model $\left(\xi_{\text {sk }}=\right.$ 200), the estimated conductivity will approach that of the skin for small values of $\psi$.

Figure 8 displays a plot of a simulated slug test and the best fit Hvorslev model, which is representative of all the low-conductivity skin cases shown in Figures $7 \mathrm{a}$ and $7 \mathrm{~b}$. As can be seen from Figure 8 , the Hvorslev model matches the simulated data extremely well. In fact, a large number of additional simulations have shown that the Hyorslev fit for the low-conductivity skin case is almost always better than that for the homogeneous case. This is especially true at small $\psi$ values (moderate to large aspect ratios), where the response data for the homogeneous case generally will display a distinct concave upward curvature [e.g., Chirlin, 1989].

At moderate to small $\psi$ values, an underlying assumption of the Hvorslev model is that there is an effective radius 


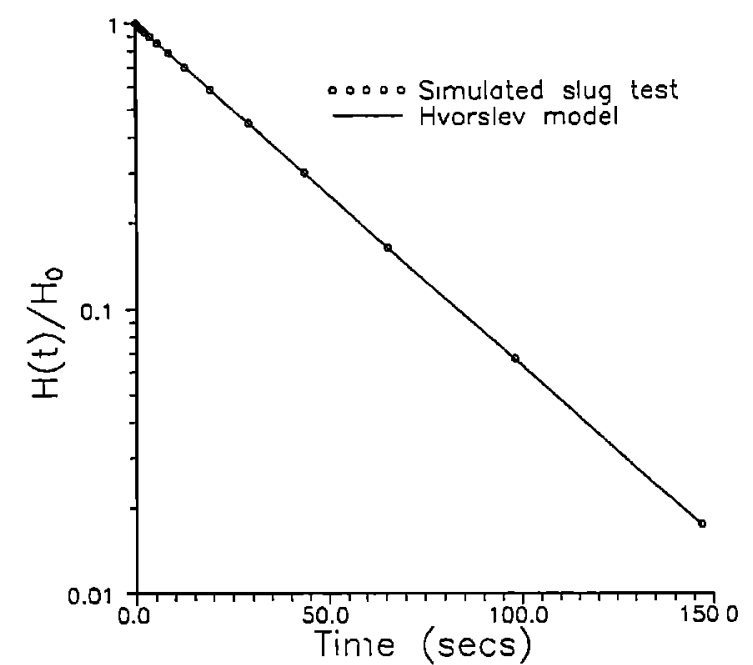

Figure 8. Normalized head versus time plot of simulated slug test and the best fit Hvorslev model for the case of a skin 2 orders in magnitude less conductive than the formation $\left(b / r_{w}=50, r_{\text {sk }}=0.10 \mathrm{~m}, r_{w}=r_{c}=0.05 \mathrm{~m}, S_{s 1}=S_{s 2}=\right.$ $1.0 \times 10^{-5} \mathrm{~m}^{-1}, K_{r 2}=K_{z 2}=0.001 \mathrm{~m} / \mathrm{s}, K_{r 1}=K_{z 1}=$ $0.00001 \mathrm{~m} / \mathrm{s}$ ).

beyond which the slug-induced disturbance has no effect on aquifer heads. In the low-conductivity skin case, this assumption is a very close approximation of reality, for almost all of the head drop occurs across the skin; heads in the formation are essentially unaffected by the slug test [e.g., Faust and Mercer, 1984]. Another major assumption of this model is that the specific storage has no influence on the response data. In most cases the thickness of the skin is relatively small, so the influence of the specific storage of the skin on slug-test responses is essentially negligible. Thus the assumptions of the Hvorslev model actually appear to be more reasonable in the low-conductivity skin case than in the homogeneous case. So, if one assumes an effective radius equal to the skin radius (e.g., $\xi_{\text {sk }}=200$ in Figure $7 \mathrm{~b}$ ), the estimated conductivity will be a reasonable approximation of the conductivity of the skin at moderate to small $\psi$ values. Hyder and Butler [1994] show that a lowconductivity skin has a similar effect on parameter estimates obtained using the Bouwer and Rice [1976] method.

Figure 9 illustrates the effect of a well skin on conductivity estimates obtained using the Cooper et al. model. In general, the effect of a skin on the Cooper et al. model estimates is similar to that seen with the Hvorslev model. Again, the effect of a low-conductivity skin is quite pronounced. If the specific storage is assumed known or constrained to physically realistic values, application of the Cooper et al. model to data from a well with a low-conductivity skin will produce an estimate that is heavily weighted toward the conductivity of the skin. In addition, there will always be a considerable deviation between the best fit Cooper et al. model and the response data in a manner similar to that shown in Figure 10. At small $\psi$ values (moderate to large aspect ratios), the combination of an excellent Hvorslev fit and a systematic deviation between the Cooper et al. model and the test data appears to be a very good indication of a low-conductivity skin. At larger $\psi$ values (lower aspect ratios), however, such a combination is also an indication of a strong component of vertical flow. Note that $M c E l w e e$ and Butler [1992] have

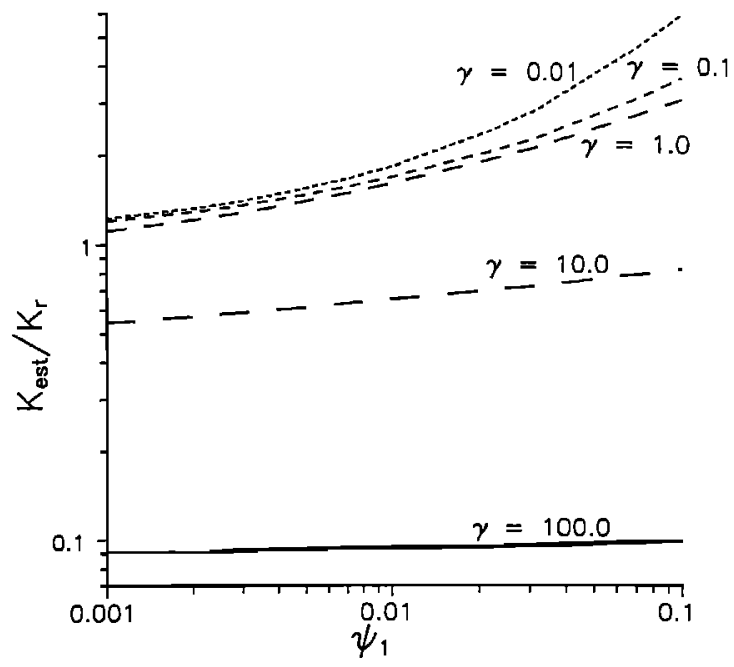

Figure 9. Plot of conductivity ratio (Cooper et al. estimate $\left(K_{\text {est }}\right)$ over actual formation conductivity $\left(K_{r}\right)$ ) versus $\psi_{1}\left(\left(K_{z 1} / K_{r 1}\right)^{1 / 2} /\left(b / r_{w}\right)\right)$ as a function of $\gamma\left(K_{r 2} / K_{r 1}\right)$ for $\xi_{\text {sk }}=2\left(\beta \approx 64, \zeta \approx 32, \alpha=1.0 \times 10^{-5}, \psi_{1}=\psi_{2}, \lambda=1\right)$.

proposed an empirical equation that relates the Cooper et al. conductivity estimate to skin and formation properties. The practical use of this equation is limited, however, since estimation of formation conductivity from the Cooper et al. estimate requires knowledge of skin conductivity and thickness.

In the high-conductivity skin case, as shown in Figures 7a and 9, conductivity estimates will be greater than the formation conductivity as a result of a considerable amount of vertical flow along the more conductive skin. The difference will be greatest at large $\psi$ values because of the larger proportion of vertical flow under those conditions. Note that the difference between the two high-conductivity skin cases ( $y=0.01$ and 0.1 ) decreases at small $\psi$ values because of the lessening importance of vertical flow. If the radius of the well

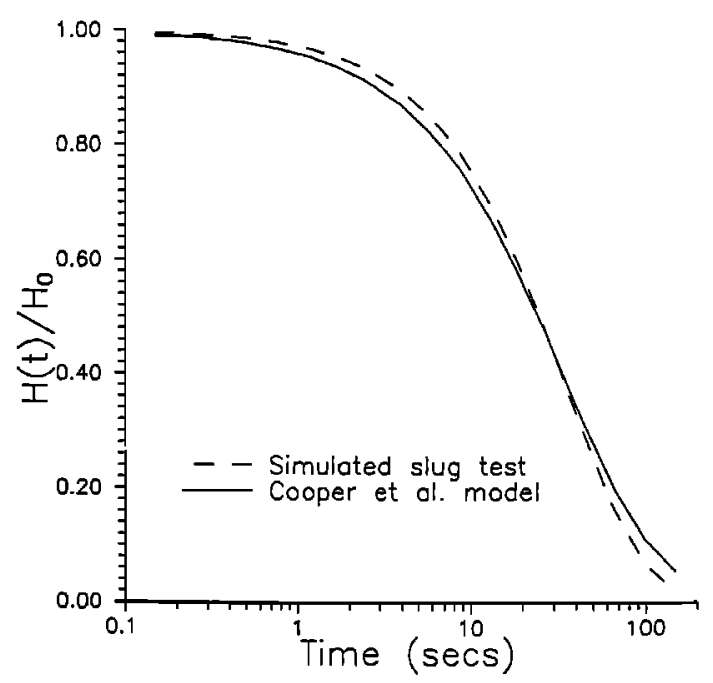

Figure 10. Normalized head versus time plot of simulated slug test and the best fit Cooper et al. model for the case of a skin 2 orders in magnitude less conductive than the formation (parameters as in Figure 8). 
screen is set to the nominal screen radius in the analysis, there will always be an offset between the high-conductivity skin cases and the homogeneous case at small $\psi$ values, as shown in Figures $7 \mathrm{a}$ and 9.

Since there is a very small head drop in the radial direction across a high-conductivity skin, one might expect that parameter estimates for the high-conductivity skin case could be considerably improved by assuming the radius of the well screen equals the radius of the high-conductivity skin. Although such an approach will decrease the offset at small $\psi$ values displayed in Figures $7 \mathrm{a}$ and 9, additional simulations have shown that the gains obtained through this approach are quite modest (less than 10\%). The reason for these smaller than might have been expected gains is that an increase in the well radius only influences $\alpha$ and $\psi$. As has been shown in plots in the previous sections, hydraulic conductivity estimates are not strongly affected by moderate changes in these dimensionless variables. The major cause of the differences between the high-conductivity skin and homogeneous cases shown in Figures $7 \mathrm{a}$ and 9 is the uncertainty concerning the screen length. Since screen length is a term in the dimensionless time variable $(\tau=$ $\left.\left(t b K_{r 2}\right) / r_{c}^{2}\right)$, an error in the screen length estimate of a certain magnitude directly translates into an error in the estimated hydraulic conductivity of the same magnitude. Thus uncertainty about the value to use for the screen length can introduce considerable error into the conductivity estimates. In the case of a partially penetrating well, the high-conductivity skin (e.g., the gravel pack) will normally be of greater length than the well screen. In this situation, the length of the high-conductivity skin, and not the nominal length of the well screen, is the quantity of interest. This larger-than-the-nominal screen length can be termed the "effective screen length" for the purposes of this discussion. In Figures $7 a$ and 9 the high-conductivity skin cases were analyzed assuming that the nominal screen length was the appropriate screen length for the analysis. At large $\psi$ values, such an approach is clearly incorrect. A more appropriate approach would have been to attempt to estimate the actual effective screen length. If there is an adequate seal in the annulus, the effective screen length should be the length of the gravel pack up to that seal. However, in cases where the length of the high-conductivity skin is considerably longer than the nominal screen length, such as in Figures 7a and 9, where the skin extends to the upper boundary of the formation, the effective screen length will be dependent on the conductivity contrast between the formation and the skin. Further work is required to develop approaches for estimation of the effective screen length in such situations.

\section{Summary and Conclusions}

A semianalytical solution to a model describing the flow of groundwater in response to a slug test in a porous formation has been presented. The primary purpose for the development of this model was to assess the viability of conventional methods for the analysis of response data from slug tests. The results of this assessment can be summarized as follows.

1. In a homogeneous formation the Cooper et al. model will provide reasonable estimates (within $25 \%$ ) of the radial component of hydraulic conductivity for $\psi$ values less than about 0.003 . For isotropic to slightly anisotropic systems, this $\psi$ range corresponds to aspect ratios greater than about
250 (much smaller aspect ratios for strongly anisotropic formations). In systems with a large dimensionless storage $(\alpha>0.01)$ the Cooper et al. model should provide reasonable estimates at virtually all commonly used aspect ratios. The viability of this model at $\psi<0.003$ is only in question for configurations with very small values of dimensionless storage $\left(\alpha<10^{-6}\right)$.

2. In a homogeneous formation the Hvorslev model (case 8) will provide reasonable estimates of the radial component of hydraulic conductivity at moderate to small values of dimensionless storage $\left(\alpha<10^{-4}\right)$ for a broad range of $\psi$ values if the magnitude of the anisotropy ratio is known. If the anisotropy ratio is not known, which is the situation commonly faced in the field, the Hvorslev model will provide reasonable estimates if the assumed anisotropy ratio is within a factor of 2-3 of the actual ratio. Table 1 allows the error introduced by the anisotropy ratio assumption to be readily assessed for any value of the assumed anisotropy. If the effective radius is assigned a value 200 times the well radius, the fully penetrating variant of the Hvorslev model (case 9) will provide reasonable conductivity estimates for $\psi$ values less than 0.01 .

3. Except in cases of large values of $\psi(>0.05)$, and very thin formations $(\beta<10)$ or well screens located very close to a boundary $(\zeta<5)$, upper or lower boundaries will have little influence on parameter estimates obtained using conventional approaches. If the formation has any degree of anisotropy in hydraulic conductivity, the range of conditions over which boundary effects are significant will be quite limited. In general, the assumption of a vertically infinite system introduces a very small amount of error into parameter estimates. Relationships developed for vertically infinite systems should thus be appropriate for most field applications.

4. In the case of a low-conductivity skin, neither the Hvorslev nor the Cooper et al. model provides reasonable estimates of hydraulic conductivity of the formation. Both approaches will yield estimates that are heavily weighted toward the conductivity of the skin. The underlying assumptions of the Hvorslev model actually appear to be more reasonable in the low-conductivity skin case than in the homogeneous case. At small $\psi$ values (moderate to large aspect ratios) the combination of an excellent fit of the Hvorslev model to the test data and a systematic deviation between the test data and the best fit Cooper et al. model appears to be a very good indication of a low-conductivity skin.

5. In the case of a high-conductivity skin the Cooper et al. model will provide reasonable estimates of formation conductivity at small $\psi$ values. The fully penetrating well variant of the Hvorslev model (effective radius 200 times the well radius) will provide viable estimates at $\psi$ values less than about 0.01 . The quality of the estimates for both models can be slightly improved if the radius of the screen is set equal to an approximate skin radius. At $\psi>0.01$ the viability of Hvorslev conductivity estimates will strongly depend on the quality of estimates for the effective screen length. In such conditions the length and radius of the gravel pack should be used in place of the nominal screen length and radius, respectively, for the analysis of the response data.

The results of this assessment indicate that there are many commonly faced field conditions in which the conventional methodology for the analysis of response data from slug tests 
appears viable. Since the definition of what constitutes a reasonable parameter estimate will be application dependent, the user can consult the figures of this paper to assess if the introduced error is acceptable for a specific application. If it appears that conventional approaches will not provide acceptable parameter estimates for a test in a particular configuration, the model developed here can be used to analyze the response data. Butler et al. [1993a] describe a series of slug tests in both consolidated and unconsolidated formations in which the model described in this article is employed for the data analysis. Considerable experience is required, however, for successful application in configurations with low-conductivity skins or a moderate degree of anisotropy owing to uncertainties introduced by a high degree of parameter correlation.

Note that the results of this study must be considered in light of the three major assumptions used in the mathematical definition of the slug-test model employed in this work. First, in (7) we adopted the commonly employed assumption of a uniform radial hydraulic gradient along the well screen as a mathematical convenience. In actuality, one would suspect that the gradient would be larger at either end of the screen, producing a U-shaped profile in the vertical plane. Butler et al. [1993b], however, have performed detailed simulations with a numerical model to show that the use of this mathematical convenience introduces a negligible degree of error to the results reported here and virtually all practical applications.

Second, in (8) and (9) we assumed that the skin fully penetrates the formation being tested. Although this assumption is appropriate for the case of multilevel slug tests performed in a well fully screened across the formation, it is clearly not representative of reality in the general case. For tests in wells with a low-conductivity skin, however, this assumption is of little significance, since a low-conductivity skin will not serve as a vertical conduit. In this situation, flow in response to a slug-induced disturbance will be primarily constrained to an interval bounded by the top and bottom of the well screen. In the case of a high-conductivity skin, this assumption will produce considerably more vertical flow in the skin than would actually occur. Butler et al. [1993b], however, have shown through numerical simulation that a slug test performed in a partially penetrating well with a high-conductivity skin that extends to the bottom of the screen is indistinguishable from a slug test performed in a similar configuration in which the well screen terminates against a lower impermeable layer. Thus for the high conductivity skin cases examined here, the slug tests were simulated assuming that the screen abutted against a lower impermeable layer. Note that this approach is only appropriate for a skin considerably more conductive (i.e., larger by a factor of 2-3) than the formation and considerably longer than the nominal screen length. Thus the highconductivity skin results presented here should be considered representative of bounding, worst case conditions.

Third, in (11) we assumed that the water table could be represented as a constant-head boundary. Given the small amount of water that is introduced to/removed from a well during a slug test, this assumption is considered reasonable under most conditions. The cases in which this assumption may be suspect are that of a well that is screened across the water table or a well screened over a deeper interval with a gravel pack that extends above the water table. Ongoing numerical and field investigations are currently being undertaken to assess the error that is introduced through this assumption and to suggest approaches for data analysis when that error is deemed unacceptably large [Butler et al., 1994b].

\section{Appendix A}

In this section the mathematical derivations of the solvtions discussed in the main body of the text are presented. For the sake of generality, the solutions are obtained in a dimensionless form. The solutions will be presented here as transform-space expressions. Details concerning the scheme used to numerically invert these expressions to real space are given in Appendix B. Note that the expressions given here are only for the head within the stressed well. Solutions for heads outside the stressed well are available from the authors upon request.

\section{Confined Aquifer Solution}

Equations (1)-(9) describe the flow conditions of interest here. To work with the most general form of the solution, this derivation is performed using dimensionless forms of (1)-(9). The dimensionless analogs of (1)-(9) are as follows:

$$
\begin{aligned}
& \frac{\partial^{2} \phi_{i}}{\partial \xi^{2}}+\frac{1}{\xi} \frac{\partial \phi_{i}}{\partial \xi}+\psi_{i}^{2} \frac{\partial^{2} \phi_{i}}{\partial \eta^{2}}=R_{i} \frac{\partial \phi_{i}}{\partial \tau} \\
& \phi_{i}(\xi, \eta, 0)=0 \quad \xi>1 \quad 0<\eta<\beta \\
& \Phi(0)=1 \\
& \phi_{2}(\infty, \eta, \tau)=0 \quad \tau>0 \quad 0 \leq \eta \leq \beta \\
& \frac{\partial \phi_{i}(\xi, 0, \tau)}{\partial \eta}=\frac{\partial \phi_{i}(\xi, \beta, \tau)}{\partial \eta}=0 \quad \xi>1 \quad \tau>0 \\
& \int_{\zeta}^{\zeta+1} \phi_{1}(1, \eta, \tau) d \eta=\Phi(\tau) \quad \tau>0 \\
& \frac{\partial \phi_{1}(1, \eta, \tau)}{\partial \xi}=\frac{\gamma}{2} \frac{d \Phi(\tau)}{d \tau} \square(\eta) \quad \tau>0 \\
& \phi_{1}\left(\xi_{\mathrm{sk}}, \eta, \tau\right)=\phi_{2}\left(\xi_{\mathrm{sk}}, \eta, \tau\right) \quad 0 \leq \eta \leq \beta \quad \tau>0 \\
& \frac{\partial \phi_{1}\left(\xi_{\text {sk }}, \eta, \tau\right)}{\partial \xi}=\gamma \frac{\partial \phi_{2}\left(\xi_{\text {sk }}, \eta, \tau\right)}{\partial \xi} \\
& 0 \leq \eta \leq \beta \quad \tau>0
\end{aligned}
$$

where

$$
\begin{array}{cc}
\phi_{i}=h_{i} / H_{0} \quad \xi=r / r_{w} \quad \eta=z / b \\
\tau=\left(t b K_{r 2}\right) /\left(r_{c}^{2}\right) & \psi_{i}=\left(A_{i} / a^{2}\right)^{0.5} \\
A_{i}=K_{z i} / K_{r i} & a=b / r_{w} \\
R_{1}=\gamma \alpha / 2 \lambda & R_{2}=\alpha / 2 \\
\lambda=S_{s 2} / S_{s 1} & \beta=B / b
\end{array}
$$




$$
\begin{aligned}
& \Phi=H / H_{0} \quad \gamma=K_{r 2} / K_{r 1} \quad \alpha=\left(2 r_{w}^{2} b S_{s 2}\right) / r_{c}^{2} \\
& \square(\eta)=0 \quad \eta<\zeta \quad \eta>\zeta+1 \\
& \square(\eta)=1 \quad \text { elsewhere } \\
& \zeta=d / b \quad \xi_{\text {sk }}=r_{\text {sk }} / r_{w} .
\end{aligned}
$$

A solution can be obtained for (A1)-(A9) through the use of integral transforms [Churchill, 1972]. A Laplace transform in time followed by a finite Fourier cosine transform in the $\eta$ direction produces a Fourier-Laplace space analog to (A1) of the following form:

$$
\frac{\partial^{2} \overline{\phi_{i}}}{\partial \xi^{2}}+\frac{1}{\xi} \frac{\partial \overline{\phi_{i}}}{\partial \xi}-\left(\psi_{i}^{2} \omega^{2}+R_{i} p\right) \overline{\phi_{i}}=0
$$

where $\overline{\phi_{i}}$ is the Fourier-Laplace transform of $\phi_{i}, f(\xi, \omega, p)$; $\omega$ is the Fourier-transform variable, equal to $(n \pi) / \beta, n=0$, $1,2, \cdots$; and $p$ is the Laplace-transform variable.

The Fourier-Laplace space solution to (A10) is quite straightforward, as (A10) is simply a form of the modified Bessel equation [Haberman, 1987]. A solution can therefore be proposed in the form

$$
\overline{\phi_{i}}=C_{i} K_{0}\left(\nu_{i} \xi\right)+D_{i} I_{0}\left(\nu_{i} \xi\right)
$$

where $\nu_{i}=\left(\psi_{i}^{2} \omega^{2}+R_{i} p\right)^{0.5} ; C_{i}, D_{i}$ are constants; $K_{i}$ is a modified Bessel function of the second kind of order $i$; and $I_{i}$ is a modified Bessel function of the first kind of order $i$.

Using the transform-space analogs of auxiliary conditions (A4) and (A6)-(A9), the constants in (A1 1) can be evaluated. Since the focus of interest in most slug tests is responses in the stressed well, only the transform-space expression for head at a radial distance of $\xi=1$ is given here:

$$
\overline{\phi_{1}}(1, \omega, p)=\frac{\gamma}{2}[1-p \Phi(p)] F_{c}(\omega) f_{1}
$$

where $\Phi(p)$ is the Laplace transform of $\Phi(t)$, the nondimensional form of $H(t) ; F_{c}(\omega)$ is the finite Fourier cosine transform of $\square(z)$, equal to

$$
\begin{aligned}
& \frac{2}{\omega} \sin \left(\frac{\omega}{2}\right) \cos \left(\frac{\omega(1+2 \zeta)}{2}\right) \quad \omega=n \pi / \beta \\
& n=1,2,3 \cdots \text {, }
\end{aligned}
$$

and equal to $1, \omega=0$;

$$
\begin{gathered}
f_{1}=\frac{\left[\Delta_{2} K_{0}\left(\nu_{1}\right)-\Delta_{1} I_{0}\left(\nu_{1}\right)\right]}{\nu_{1}\left[\Delta_{2} K_{1}\left(\nu_{1}\right)+\Delta_{1} I_{1}\left(\nu_{1}\right)\right]} \\
\Delta_{1}=K_{0}\left(\nu_{1} \xi_{\text {sk }}\right) K_{1}\left(\nu_{2} \xi_{\text {sk }}\right)-\left(\frac{N}{\gamma}\right) K_{0}\left(\nu_{2} \xi_{\text {sk }}\right) K_{1}\left(\nu_{1} \xi_{\text {sk }}\right) ; \\
\Delta_{2}=I_{0}\left(\nu_{1} \xi_{\text {sk }}\right) K_{1}\left(\nu_{2} \xi_{\text {sk }}\right)+\left(\frac{N}{\gamma}\right) K_{0}\left(\nu_{2} \xi_{\text {sk }}\right) I_{1}\left(\nu_{1} \xi_{\text {sk }}\right) ; \\
N=\nu_{1} / \nu_{2} .
\end{gathered}
$$

The application of an inverse finite Fourier cosine transform to (A12) for $\eta$ within the screen and utilization of the Laplace-space analog of (A6) produces the following expression for head in the stressed well:

$$
\Phi(p)=\frac{\gamma}{2}[1-p \Phi(p)] \Omega
$$

where

$$
\Omega=\int_{\zeta}^{\zeta+1}\left\{F_{e}^{-1}\left[F_{c}(\omega) f_{1}\right]\right\} d \eta
$$

$F_{c}^{-1}$ is the inverse finite Fourier cosine transform.

Solving for $\Phi(p)$ yields

$$
\Phi(p)=\frac{(\gamma / 2) \Omega}{[1+(\gamma / 2) p \Omega]}
$$

Appendix B provides details of the fast Fourier transform scheme used to invert the expression in the $\Omega$ term. The algorithm of Stehfest [1970] was used to perform the numerical Laplace inversion of (A14).

\section{Unconfined Aquifer Solution}

For the unconfined case, (A5) is replaced by the dimensionless analogs of (11) and (12):

$$
\begin{array}{ccc}
\phi_{i}(\xi, 0, \tau)=0 & \xi>1 & \tau>0 \\
\frac{\partial \phi_{i}(\xi, \beta, \tau)}{\partial \eta}=0 & \xi>1 & \tau>0
\end{array}
$$

A solution for (A1)-(A4), (A6)-(A9), and (A15)-(A16) is obtained using the same approach as in the confined case. The Fourier-Laplace expression for head at a radial distance of $\xi=1$ in the unconfined case can be written as

$$
\overline{\phi_{1_{\mathrm{uc}}}}\left(1, \omega^{*}, p\right)=\frac{\boldsymbol{\gamma}}{2}\left[1-p \Phi_{\mathrm{uc}}(p)\right] F_{s}\left(\omega^{*}\right) f_{1}
$$

where $\overline{\phi_{1_{u c}}}$ is the Fourier-Laplace transform of $\phi_{1_{\mathrm{uc}}}$, the nondimensional form of $h_{1}$ for the unconfined case; $\Phi_{\mathrm{uc}}(p)$ is the Laplace transform of the nondimensional form of $H(t)$ for the unconfined case; $F_{s}\left(\omega^{*}\right)$ is the modified finite Fourier sine transform of $\square(z)$, equal to

$$
\frac{2}{\omega^{*}} \sin \left(\frac{\omega^{*}(2 \zeta+1)}{2}\right) \sin \left(\frac{\omega^{*}}{2}\right)
$$

and $\omega^{*}$ is the Fourier transform variable for the modified sine transform, equal to $(n \pi) / 2 \beta, n=1,3,5, \cdots$.

The application of an inverse modified finite Fourier sine transform to (A 17) for $\eta$ within the screen and rewriting in terms of $\Phi_{\mathrm{uc}}(p)$ produces the following expression:

$$
\Phi_{\mathrm{uc}}(p)=\frac{(\gamma / 2) \Omega^{*}}{\left[1+(\gamma / 2) p \Omega^{*}\right]}
$$

where

$$
\Omega^{*}=\int_{\zeta}^{\zeta+1}\left\{F_{s}^{-1}\left[F_{s}\left(\omega^{*}\right) f_{1}\right]\right\} d \eta
$$

The modified finite Fourier sine transform employed in the unconfined case requires a bit of discussion. The standard finite Fourier sine transform is quite useful when a constant head is maintained at both boundaries. In the unconfined case the upper boundary $(\eta=0)$ is defined as a constant- 
head condition, while the lower boundary $(\eta=\beta)$ is defined as a no-flow condition. Churchill [1972] presents the modified finite Fourier sine transform

$$
F_{s}(n)=\int_{0}^{\beta} f(\eta) \sin \left(\frac{n \pi \eta}{2 \beta}\right) d \eta \quad n=1,3,5, \cdots
$$

as an example of a Sturm-Liouville transformation. When this modified sine transform is applied to the second-order derivative with respect to $\eta$, integration by parts yields

$$
\begin{array}{r}
\int_{0}^{\beta} \frac{\partial^{2} \phi_{i}}{\partial \eta^{2}} \sin \left(\frac{n \pi \eta}{2 \beta}\right) d \eta=-\omega^{* 2} \overline{\phi_{i}}+\omega^{*} \phi_{i}(0) \\
-(-1)^{n} \frac{\partial \phi_{i}(\beta)}{\partial \eta}
\end{array}
$$

where

$$
\omega^{*}=(n \pi) / 2 \beta \quad n=1,3,5, \cdots
$$

For the boundary conditions employed here, (A20) reduces to

$$
-\omega^{* 2} \overline{\phi_{i}}
$$

\section{Appendix B}

In this section, details are presented of the procedures employed to numerically invert the transform-space expressions derived in Appendix A. As discussed in the main text, the fast Fourier transform (FFT) procedure was employed to perform the required Fourier transforms/inversions in this work. In order to demonstrate that the discrete Fourier transforms introduced negligible error into the numerically inverted solution, a comparison between the discrete solution and the continuous form is discussed.

For the confined case (cf. (A14)), a finite Fourier cosine transform was employed. The continuous form of this transform can be written as

$$
F_{c}(n)=\int_{0}^{\beta} f(\eta) \cos \left(\frac{n \pi \eta}{\beta}\right) d \eta
$$

where $F_{c}$ is the finite Fourier cosine transform and $f(\eta)=$ $F_{c}(\omega) f_{1}$.

In order to utilize the FFT procedure, (B1) is approximated using a discrete Fourier transform:

$$
\begin{array}{r}
F_{c}(n) \approx \Delta \sum_{k=0}^{N-1} f(\Delta k) \cos \left(\frac{n \pi k}{N}\right) \\
n=0,1,2, \cdots, N-1
\end{array}
$$

where $N$, the number of equally spaced points between 0 and $\beta$, must be an integer power of 2 ; and $\Delta$ is the interval between equally spaced points, equal to $\beta / N$.

For the unconfined case (cf. (A18)) a modified finite Fourier sine transform was employed. The continuous form of this transform can be written as

$$
F_{s}(n)=\int_{0}^{\beta} f_{\mathrm{uc}}(\eta) \sin \left(\frac{n \pi \eta}{2 \beta}\right) d \eta \quad n=1,3,5, \cdots
$$

where $F_{s}$ is the modified finite Fourier sine transform and $f_{\mathrm{uc}}(\eta)=F_{s}\left(\omega^{*}\right) f_{1}$. Equation (B3) is only defined for odd-numbered $n$. For ready implementation with standard FFT algorithms, (B3) is rewritten in terms of a continuous sequence of $n$ :

$$
\begin{array}{r}
F_{s}(n)=\frac{\left[1+(-1)^{n+1}\right]}{2} \int_{0}^{\beta} f_{\mathrm{uc}}(\eta) \sin \left(\frac{n \pi \eta}{2 \beta}\right) d \eta \quad \\
n=1,2,3, \cdots
\end{array}
$$

Equation (B4) is now approximated using a discrete Fourier transform:

$$
\begin{array}{r}
F_{s}(n) \approx \frac{\left[1+(-1)^{n+1}\right]}{2} \Delta \sum_{k=1}^{N-1} f_{\mathrm{uc}}(\Delta k) \sin \left(\frac{n \pi k}{2 N}\right) \\
n=1,2, \cdots, N-1
\end{array}
$$

Equations (B2) and (B5) can be directly implemented in standard FFT algorithms. In this work an FFT algorithm given by Press et al. [1992] was employed. The total number of sampling points $(N)$ in $\eta$ was constrained, such that there would always be at least 10 points within the screened interval.

In order to check on the approach outlined above, an additional series of simulations was performed in which the continuous forms of the finite Fourier transforms were employed for the required transforms/inversions. The $\Omega$ term that is employed in (A14) can be written in the continuous form as

$\Omega=\frac{f_{1}(n=0)}{\beta}+\frac{8 \beta}{\pi^{2}} \sum_{n=1}^{\infty} \frac{f_{1}(n)}{n^{2}} \sin ^{2} \frac{n \pi}{2 \beta} \cos ^{2}\left(\frac{n \pi(1+2 \zeta)}{2 \beta}\right)$

The $\Omega^{*}$ that is employed in (A18) can be written in continuous form as

$$
\begin{aligned}
\Omega^{*}= & \frac{16 \beta}{\pi^{2}} \sum_{n=1}^{\infty} \\
& \cdot\left[1+(-1)^{n+1}\right] \frac{f_{1}(n)}{n^{2}} \sin ^{2} \frac{n \pi}{4 \beta} \sin ^{2}\left(\frac{n \pi(1+2 \zeta)}{4 \beta}\right)
\end{aligned}
$$

In all cases the inversion of (B6) and (B7) produced results that were virtually indistinguishable from those found using an FFT algorithm with (B2) and (B5). The computational time, however, was significantly greater.

The inverse Laplace transform, the final step of the numerical inversion procedure, was performed here using the algorithm of Stehfest [1970]. Sixteen terms were used in the summation of the Stehfest algorithm for all the cases examined in this work. Note that the procedures discussed here are implemented in a series of Fortran programs found in the work by Hyder et al. [1993]. 
Acknowledgments. This research was sponsored in part by the Air Force Office of Scientific Research, Air Force Systems Command, USAF, under grant or cooperative agreement number AFOSR 91-0298. This research was also supported in part by the Department of the Interior, U.S. Geological Survey, through the Kansas Water Resources Research Institute. The views and conclusions contained in this document are those of the authors and should not be interpreted as necessarily representing the official policies, either expressed or implied, of the U.S. government.

\section{References}

Amoozegar, A., and A. W. Warrick, Hydraulic conductivity of saturated soils: Field methods, in Methods of Soil Analysis, Part 1, Physical and Mineralogical Methods, Agron. Monogr. Ser. 9, edited by A. Klute, pp. 735-770, American Society of Agronomy, Madison, Wisc., 1986.

Bliss, J. C., and K. R. Rushton, The reliability of packer tests for estimating the hydraulic conductivity of aquifers, $Q$. J. Eng. Geol., 17, 81-91, 1984.

Bohling, G. C., and C. D. McElwee, SUPRPUMP: An interactive program for well test analysis and design, Ground Water, 30(2), 262-268, 1992.

Bouwer, H., The Bouwer and Rice slug test-An update, Ground Water, 27(3), 304-309, 1989.

Bouwer, H., and R. C. Rice, A slug test for determining hydraulic conductivity of unconfined aquifers with completely or partially penetrating wells, Water Resour. Res., 12(3), 423-428, 1976.

Brigham, E. O., The Fast Fourier Transform, 252 pp., PrenticeHall, Englewood Cliffs, N. J., 1974.

Butler, J. J., Jr., and Z. Hyder, An assessment of the Nguyen and Pinder method for slug test analysis, KGS Open File Rep. 93-46, 25 pp., Kansas Geol. Surv., Lawrence, 1993.

Butler, J. J., Jr., and C. D. McElwee, Hydrogeologic characterization of hazardous waste sites, Contrib. Kans. Water Resour. Res. Inst., 283, 114 pp., 1990.

Butler, J. J., Jr., W. Z. Liu, and D. P. Young, Analysis of October 1993 slug tests in Stafford, Pratt, and Reno Counties, southcentral Kansas, KGS Open File Rep. 93-52, 70 pp., Kans. Geol. Surv., Lawrence, 1993a.

Butler, J. J., Jr., C. D. McElwee, and Z. Hyder, Slug tests in unconfined aquifers, Contrib. Kans. Water Resour. Res. Inst., 303, 67 pp., 1993b.

Butler, J. J., Jr., G. C. Bohling, Z. Hyder, and C. D. McElwee, The use of slug tests to describe vertical variations in hydraulic conductivity, J. Hydrol., 156, 137-162, 1994a.

Butler, J. J., Jr., C. D. McElwee, and Z. Hyder, Slug tests in unconfined aquifers-Year two, Contrib. Kans. Water Resour. Res. Inst., 310, 1994b.

Chirlin, G. R., A critique of the Hvorsiev method for slug test analysis: The fully penetrating well, Ground Water Monit. Rev., 9(2), 130-138, 1989.

Chirlin, G. R., The slug test: The first four decades, Ground Water Manage., 1, 365-381, 1990.

Churchill, R. V., Operational Mathematics, 481 pp., McGraw-Hill, New York, 1972.

Cooley, J. W., and J. W. Tukey, An algorithm for machine calculations of complex Fourier series, Math. Comput., 19, 297-301, 1965.

Cooper, H. H., Jr., J. D. Bredehoeft, and I. S. Papadopulos, Response of a finite-diameter well to an instantaneous charge of water, Water Resour. Res., 3(1), 263-269, 1967.
Dagan, G., A note on packer, slug, and recovery tests in unconfined aquifers, Water Resour. Res., 14(5), 929-934, 1978.

Dougherty, D. E., and D. K. Babu, Flow to a partially penetrating well in a double-porosity reservoir, Water Resour. Res., 20(8), 1116-1122, 1984.

Faust, C. R., and J. W. Mercer, Evaluation of slug tests in wells containing a finite-thickness skin, Water Resour. Res., 20(4), 504-506, 1984.

Freeze, R. A., and J. A. Cherry, Groundwater, 604 pp., PrenticeHall, Englewood Cliffs, N. J., 1979.

Haberman, R., Elementary Applied Partial Differential Equations, 547 pp., Prentice-Hall, Englewood Cliffs, N. J., 1987.

Hayashi, K., T. Ito, and $\mathrm{H}$. Abe, A new method for the determination of in situ hydraulic properties by pressure pulse tests and application to the Higashi Hachimantai geothermal field, $J$. Geophys. Res., 92(B9), 9168-9174, 1987.

Hvorslev, M. J., Time lag and soil permeability in ground-water observations, Bull. 36, 50 pp., Waterw. Exp. Sta., U.S. Army Corps of Eng., Vicksburg, Miss., 1951.

Hyder, Z., Analysis of slug tests in partially penetrating wells, $\mathrm{Ph} . \mathrm{D}$. thesis, Univ. of Kans., Lawrence, 1994.

Hyder, Z., and J. J. Butler Jr., Slug tests in unconfined formations: An assessment of the Bouwer and Rice technique, Ground Water, in press, 1994.

Hyder, Z., W. Z. Liu, and J. J. Butler Jr., Software for the evaluation of semianalytical solutions for slug tests in partially penetrating wells, KGS Comput. Program Ser. 93-1, 42 pp., Kans. Geol. Surv., Lawrence, 1993.

Kruseman, G. P., and N. A. de Ridder, Analysis and evaluation of pumping test data, ILRI Publ. 47, 377 pp., Int. Inst. for Land Reclamation and Improvement, The Netherlands, 1989.

McElwee, C. D., and J. J. Butler Jr., Effective transmissivities from slug tests in wells with a skin, KGS Open File Rep. 92-12, 31 pp., Kans. Geol. Surv., Lawrence, 1992.

Moench, A. F., and P. A. Hsieh, Analysis of slug test data in a well with finite-thickness skin, Mem. IAH Int. Congr. Hydrogeol. Rocks Low Permeability, 17(2), 17-29, 1985.

Moench, A., and A. Ogata, Analysis of constant discharge wells by numerical inversion of Laplace transform solutions, in Groundwater Hydraulics, Water Resour. Monogr., vol. 9, edited by J. Rosenshein and G. D. Bennett, pp. 146-170, AGU, Washington, D. C., 1984.

Nguyen, V., and G. F. Pinder, Direct calculation of aquifer parameters in slug test analysis, in Groundwater Hydraulics, Water Resour. Monogr., vol. 9, edited by J. Rosenshein and G. D. Bennett, pp. 222-239, AGU, Washington, D. C., 1984.

Press, W. H., S. A. Teukolsky, W. T. Vetterling, and B. P. Flannery, Numerical Recipes in FORTRAN, 963 pp., Cambridge University Press, New York, 1992.

Stehfest, H., Numerical inversion of Laplace transforms, Commun. $A C M, 13(1), 47-49,1970$.

U.S. Department of the Navy, Bureau of Yards and Docks, Design Manual: Soil Mechanics, Foundations, and Earth Structures, vol. DM-7, chap. 4, Alexandria, Va., 1961.

J. J. Butler Jr., Z. Hyder, W. Liu, and C. D. McElwee, Kansas Geological Survey, University of Kansas, 1930 Constant Avenue, Lawrence, KS 66047.

(Received July 6, 1993; revised June 13, 1994; accepted June 23,1994 .) 